Research Journal of Applied Sciences 5 (3): 161-164, 2010

ISSN: $1815-932 \mathrm{X}$

(C) Medwell Journals, 2010

\title{
Effect of Substrates of Spawn Production on Mycelial Growth of Oyster Mushroom Species
}

\author{
${ }^{1}$ O.H. Stanley and ${ }^{2}$ G.D. Awi-Waadu \\ ${ }^{1}$ Department of Microbiology, \\ ${ }^{2}$ Department of Animal and Environmental Biology, \\ University of Port Harcourt, P.M.B. 5323, Port Harcourt, Nigeria
}

\begin{abstract}
Spawn quality is the most important factor in the production of edible mushroom (which is fast gaining prominence in Nigeria and Africa at large). In order to determine the effects of substrates spawn preparation on mycelial growth of oyster mushroom species, the experiment was conducted in a factorial experiment design at randomized completely with three replications. In this experiment, first and second factors, respectively were substrates (Wheat, yellow maize, guinea corn, millet, red sorghum and white maize, Bende local and oyster mushroom species (Pleurotus tuber-regium and pelurotus pulmonarius). The results clearly demonstrated that between various substrates used, maximum and minimum growth rate were recorded for white maize (Bende Local) and least mycelial extension and fresh weight on wheat. The second best grain for both species used was Red Sorghum.
\end{abstract}

Key words: Mycelial growth, oyster mushroom, spawn grains, yellow maize, guinea corn, millet

\section{INTRODUCTION}

Mushroom spawn is the mushroom mycelium growing on a given substrate. It serves as the planting material in mushroom cultivation. To produce spawn, inoculate a pasteurized medium, usually grain, with the sterile culture of a particular mushroom species. After the culture has grown throughout the medium, it is called spawn. It is actually the first stage of mushroom production. Spawn quality is counted the most important part in mushroom production (Mohammadi Goltapeh and Purjam, 2003) spawn production is a very technical process and requires a lot of expertise and specialized knowledge and care on the part of people producing it (Chinda and Chinda, 2007). It is infact the bedrock of the mushroom industry and the limiting factor to mushroom cultivation or production all over the world.

In nature mushrooms use spores for generative multiplication and these are microscopic and difficult to handle (Oei, 1991). Alternatively, tissue cultures taken from cap-tissues may be used to prepare spawn. In time, the mycelium completely grows through the grain. The fully colonized grain (spawn) is used to seed already prepared substrates agricultural and non-agricultural wastes) for mushroom production. Grain spawn is in common use because of its ability to ramify the substrate faster and ease of planting (Bahl, 1988). Spawn grains such as wheat, millet and corn have been reported to affect carpophores production (Nwanze et al., 2005b) and there are various additives that are known to stimulate fruiting. They include rice bran, cassava peels and soybean powder. Nwanze et al. (2005a) examined the effect of spawn grains such as weat, millet and corn on the culture of lentinus squarrosulus. The results showed that corn spawn induced highest yield and dry weight of fruiting as compared to wheat and millet spawn.

Environmental factors such as temperature, $\mathrm{O}_{2}, \mathrm{Co}_{2}$, humidity, light and $\mathrm{pH}$ have been reported also to affect mycelia growth in the spawn preparation (Nwanze et al., 2005b). The present study to determine the effect of various grains on spawn production of pleurotus tuberregium and $\mathrm{P}$. pulmonarius was carried out in the Laboratory of Dilomat farms ( $\left(\mathrm{N}^{\circ} 48^{\prime} 22^{\prime \prime}, \mathrm{N} 6^{\circ} 58^{\prime} 48.7^{\prime \prime} \mathrm{E}\right.$ and Elevation 16) located in the Rivers State University of Science and Technology, Nkpolu, Port Harcourt in the Niger Delta Region of Nigeria.

\section{MATERIALS AND METHODS}

Sources of materials: The mushroom species used for this research were supplied by Dilomat Farms and Services Ltd located in the Rivers State University of Science and Technology, Nkpolu, Port Harcourt. The grains used white maize, broadbende local, red sorahum, guinea corn, yellow maize, millet and wheat were purchased from mile 3 market in Diobu, Port Harcourt.

Corresponding Author: O. Herbert Stanley, Department of Microbiology, University of Port Harcourt, P.M.B. 5323, Port Harcourt, Nigeria 


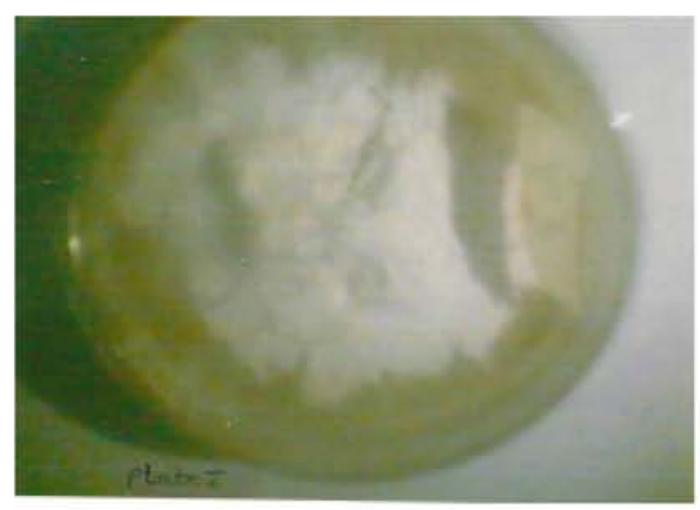

Fig. 1: Mycelia Growth of $P$. tuber-rigium

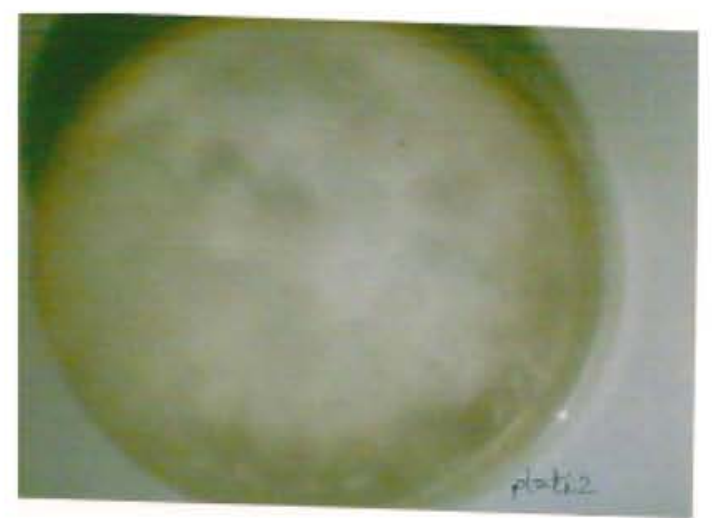

Fig. 2: Mycelia Growth of $P$. pulmonarius

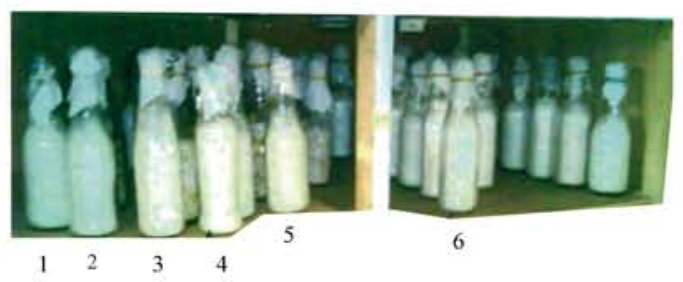

Fig. 3: Spawn grains

Preparation of culture medium: Potato Dextrose Agar (PDA) was employed as medium of growth for culturing pleurotus tuber-regium and pleurotus pulmonarius PDA was prepared as described by oxoid manual. For $1 \mathrm{~L}$ of the culture medium prepared, $2.00 \mathrm{~g}$ of thirly peeled and sliced Irish potatoes; $20 \mathrm{~g}$ of glucose; $20 \mathrm{~g}$ of agar powder and $1 \mathrm{~L}$ distilled water were used.

Culture of fungi: Fresh cultures of $P$. tuber-regium and $P$. pulmonarius were used with a sterilized razor, a small piece of the mushroom tissue was removed and placed on PDA medium in Petridishes. The inoculated dishes were incubated at $27^{\circ} \mathrm{C}$ for 10 days. Several sub-culturings were made until pure cultures were obtained (Fig. 1 and 2).
Spawn preparation: Total $250 \mathrm{~g}$ each of white maize (local bende), red sorghum, guinea corn, yellow maize, millet and wheat seeds were washed in clean water three times to remove chaff, dust and other particles. The grains were then soaked in water for $24 \mathrm{~h}$ for maxiumum absorption of water. Soaked grains were again washed in water drained and put into spawn bottles. About $2 / 3$ of each spawn bottle were filled with grains of each type and mixed with $5 \mathrm{~g}$ of calcium carbonate $\left(\mathrm{CaCO}_{3}\right)$ after which they were autoclaved at $121^{\circ} \mathrm{C}$ (at a pressure of $1 \mathrm{~kg} \mathrm{~cm}^{-2}$ ) for $2 \mathrm{~h}$ each day, for 3 consecutive days. The grains in the bottles were then inoculated with three $9 \mathrm{~mm}$ mycetial discs per bottle (triplicate of each grain type) under aseptic condition (Fasidi and Kadiri, 1993). These were incubated at $27+1^{\circ} \mathrm{C}$ (Fig. 3). On 9th day of incubation, $1=$ Millet, $2=$ Gunea Corn, $3=$ Red Sorghum, $4=$ White Maize, $5=$ Yellow Maize, $6=$ Wheat. Mycelia fresh weight (grains) was determined as follows:

- Weight (wt) of bottle $=x g$

- Weaght of bottle and spawn grains $=(X+Y) g$

- Weaght of bottle + wt of spawn grains $+w t$ of fresh mycelia $=(\mathrm{X}+\mathrm{Y}+\mathrm{Z}) \mathrm{g}$

- Fresh mycelial wt. $=(\mathrm{X}+\mathrm{Y}+\mathrm{Z})-(\mathrm{X}+\mathrm{Y}) \mathrm{g}=\mathrm{Zg}$. A Ruler was used to measure the mycelial extension in $\mathrm{cm}$.

\section{RESULTS AND DISCUSSION}

White maize (Bende Local) was found to be most favourable to mycelial extension and mycelial fresh weight of $P$. tuber regium and P. pulmonarius. The result of the analysis of variance (Table 1 and 2) showed that the mean mycelial fresh weight were $3.767 \pm 0.030 \mathrm{~cm}$ and $1.583 \pm 0.0099$, respectively for $P$. tuber-regium on the 6 th day of incubation. In the case of $P$. pulmonarius, the mean mycelial extension and mean myucelial fresh weight were $3.622 \pm 0.032 \mathrm{~cm}$ and $1.137 \pm 0.008 \mathrm{~g}$. Red sorghum was next to white maize with mean value for mycelial extension and mycelial fresh weight were $2.311 \pm 0.032 \mathrm{~cm}$ and $0.922 \pm 0.008 \mathrm{~g}$. All the substrates supported the growth of mycelia of the two pleurotus species studied but in varying degrees. The least support for both species studied was shown by wheat (Table 1 and 2).

In all substrates $P$. tuber-regium did better than P. pulmonarius in terms of mean mycelial extension and mean mycelial fresh weight except on red sorghum whee $P$. pulmonarius was better.

Tinoco et al. (2001) found that larger surface are a and pore of substrates support more mycelium growth rate. This could account for the result recorded by white maize (bende Local). It is a floury maize grain whose grains were larger than other substrates used in this 
Res. J. Applied Sci., 5 (3): 161-164, 2010

Table 1: Effect of various grains on spawn production of P. tuber-regium

\begin{tabular}{lcc} 
Types of grain & $\begin{array}{c}\text { Mycelial extension } \\
(\text { Mean } \pm \text { SE) }\end{array}$ & $\begin{array}{c}\text { Mycelial fresh weight } \\
(\text { Mean } \pm \text { SE) }\end{array}$ \\
\hline Wheat & $1.572 \pm 0.030^{\mathrm{a}}$ & $0.517 \pm 0.009^{\mathrm{a}}$ \\
Yellow maize & $1.750 \pm 0.030^{\mathrm{b}}$ & $0.683 \pm 0.009^{b}$ \\
Guinea corn & $2.011 \pm 0.030^{\mathrm{c}}$ & $0.717 \pm 0.009^{\mathrm{c}}$ \\
Millet & $2.028 \pm 0.030^{\mathrm{c}}$ & $0.761 \pm 0.009^{\mathrm{d}}$ \\
Red sorghum & $2.089 \pm 0.030^{\mathrm{c}}$ & $0.844 \pm 0.009^{\mathrm{c}}$ \\
White maize & $3.767 \pm 0.030^{\mathrm{d}}$ & $1.583 \pm 0.009^{\mathrm{f}}$ \\
\hline
\end{tabular}

Means with same superscript along the same column are not significantly different from each other at $p<0.05$

Table 2: Effect of various grains on spawn production of P. pulmonarious

\begin{tabular}{lcc}
\hline Types of grain & Mycelial extension & Mycelial fresh weight \\
\hline Wheat & $1.583 \pm 0.032^{\mathrm{a}}$ & $0.483 \pm 0.008^{\mathrm{a}}$ \\
Yellow maize & $1.678 \pm 0.032^{\mathrm{b}}$ & $0.550 \pm 0.008^{\mathrm{b}}$ \\
Guinea corn & $1.783 \pm 0.032^{\mathrm{c}}$ & $0.633 \pm 0.008^{\mathrm{c}}$ \\
Millet & $2.107 \pm 0.032^{\mathrm{d}}$ & $0.683 \pm 0.008^{\mathrm{d}}$ \\
Red sorghum & $2.311 \pm 0.032^{\mathrm{e}}$ & $0.922 \pm 0.008^{\mathrm{e}}$ \\
White maize & $3.622 \pm 0.032^{\mathrm{f}}$ & $1.137 \pm 0.008^{\mathrm{f}}$ \\
\hline
\end{tabular}

Means with same superscript along the same column are not significantly different from each other at $p<0.05$

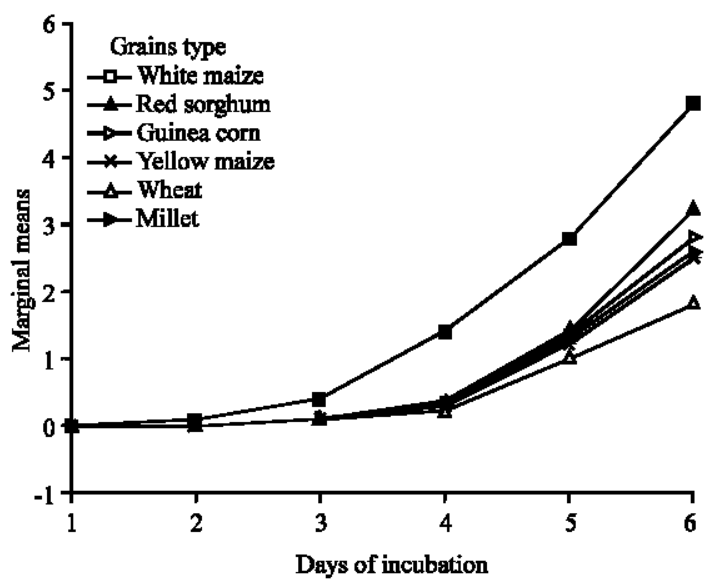

Fig. 4: The trend of day of incubation on different grain type of mycelia extension of $P$. tuber-regium

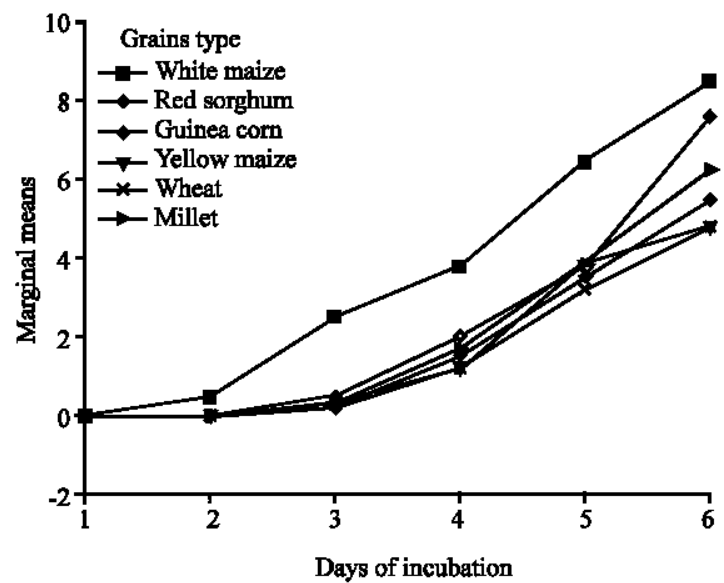

Fig. 5: The trend of day of incubation on different grain type of mycelia extension of $P$. pulmonarious

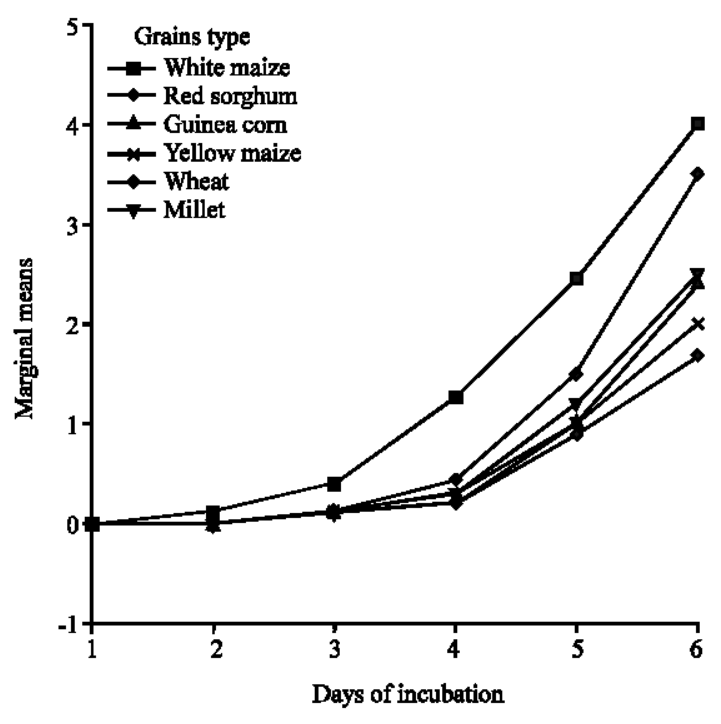

Fig. 6: The trend of day of incubation on different grain type of mycelial fresh weight of $P$. pulmonarious

study. It consists largely of soft starch which is surrounded by the coneous layer under the pericarp. This maize is grown mainly in the southern part of Nigeria. The trend of day of incubation on different grain type of mycelial fresh weight for the two spcies studied are shown in Fig. 4-6 with white maize as the best substrate.

On the 10th day of incubation, the white maize were fully colonized by vigorously growing mycelium of the studied species whereas the red sorghum was fully colonized by the two species on the 12th day. The other substrates (guinea corn, yellow maize, wheat and millet) were fully colonized on the 14th day of incubation.

\section{CONCLUSION}

Mycelial growth of $P$. tuber-regium were faster than that of $P$. pulmoniarius on all the substrates used except on red sorghum.

The best substrate for spawn preparation was white maize (bende-local) from the south Eastern part of Nigeria. therefore, all to patronize Nigeria by purchasing the most suitable grain for spawn preparation as this will support the production of high quality and quantity of edible mushroom in Africa and the world at large.

Because of the important role edible mushrooms play in diet, waste management health management/ medicine, environmental sustainability and potentials to 
enhance the economics of Nations, Mushroom farming and research should be encouraged in all nations by setting up good spawn preparation centres.

\section{REFERENCES}

Bahl, N., 1988. Handbook on Mushrooms. 2nd Edn., Oxford and IBH Publishing Co. Ltd., New Delhi, Bombay, pp: 52.

Chinda, M.M. and F. Chinda, 2007. Mushroom Cultivation for Health and Wealth. Apapa Printers and Converters Ltd., Lagos, pp: 64-65.

Fasidi, I.O. and M. Kadiri, 1993. Use of grains and agricultural waste for the cultivation of lentinus subnudus in Nigeria. Rivista Biol. Trop., 41: 411-415.

Mohammadi Goltapeh, E. and E. Purjam, 2003. Principles of Mushroom Cultivation. Tarbiat Modarres University Press, UK., pp: 604.
Nwanze, P.I., A.U. Khan, A.U. Ameh and V.J. Umoh, 2005a. The effect of the interaction of various spawn grains with different culture medium on carpophores dry weights and stipe and pileus diameters of Lentinus squarrosulus (Mon.) Singer. Afr. J. Biotechnol., 4: 615-619.

Nwanze, P.I., J.B. Ameh and V.J. Umoh, 2005b. The effect of the interaction of various oil types with different culture media on biomass production of Psathyrella atroumbonata pegler. Afr. J. Biotechnol., 4: 1285-1289.

Oei, P., 1991. Manual on Mushroom Cultivation Technique, Species and Opportunities for Commercial Applications in Developing Countries. 1st Edn., Tool Foundation, Amsterdam, pp: 249.

Tinoco, R., M.A. Pickard and R. Vazquez Duhalt, 2001. Kinetic differences of purified laccases from six Pleurotus ostreatus strains. Lett. Applied Micobiol., 32: 331-335. 